\title{
Association of XPC Polymorphisms with Cutaneous Malignant Melanoma Risk: Evidence from a Meta-Analysis
}

\author{
Fatemeh Asadian ${ }^{1}$, Seyed Mohammadreza Niktabar ${ }^{2, *}$, Yaser Ghelmani ${ }^{3}$, Shadi Kargar ${ }^{2}$, Elahe Akbarian ${ }^{4}$, \\ Seyed Alireza Emarati ${ }^{4}$, Jalal Sadeghizadeh-Yazdi ${ }^{5}$, Hossein Neamatzadeh ${ }^{6,7}$
}

\section{ABSTRACT}

Background: A number of studies have reported that the xeroderma pigmentosum complementation group C (XPC) polymorphisms are associated with cutaneous malignant melanoma (CMM) susceptibility. But the results of those studies were inconsistent. Here, we performed a study to obtain a more conclusive result on the association of XPC polymorphisms with risk of CMM.

Methods: The XPC Lys939Gln and Ala499Val polymorphisms were genotyped in 150 CMM cases and 150 controls by PCR-RFLP assay. Subsequently, all published relevant studies were identified through a comprehensive literature search in PubMed, Web of Science, and CNKI databases. Odds ratios (ORs) and 95\% confidence intervals (Cls) were calculated to estimate the strength of correlation.

Results: There was no significant association between XPC Lys939Gln and Ala499Val polymorphisms and CMM risk in our population. A total of 15 case-control studies including ten studies with 5,990 cases and 7,697 controls on XPC Lys939Gln and five studies with 3,139 cases and 3,721 controls on XPC Ala499Val polymorphism were selected. Pooled data revealed that XPC Lys939Gln (C vs. A: OR $=1.108,95 \% \mathrm{Cl} 1.008-$ 1.217; $P=0.033$ ) and Ala499Val (C vs. $A: O R=0.918,95 \% C l ~ 0.850-0.992 ; p=0.031 ; C C+C A$ vs. $A A: O R=0.904,95 \% C l 0.819-0.997 ; p=0.043$ ) polymorphisms were significantly associated with an increased risk of CMM. Moreover, stratified analyses by ethnicity revealed that the XPC Ala499Val and Lys939Gln polymorphisms were significantly associated with risk of CMM in Caucasians and mixed populations, respectively. Conclusions: This meta-analysis result suggested that XPC Lys939Gln and Ala499Val polymorphisms were significantly associated with risk of CMM.

\section{KEYWORDS}

cutaneous melanoma; malignant melanoma; XPC gene; polymorphism; meta-analysis

\section{AUTHOR AFFILIATIONS}

${ }^{1}$ Department of Medical Laboratory Sciences, School of Paramedical Science, Shiraz University of Medical Sciences, Shiraz, Iran

2 Department of Surgery, Shahid Sadoughi University of Medical Sciences, Yazd, Iran

${ }^{3}$ Clinical Research Development Center of Shahid Sadoughi Hospital, Shahid Sadoughi University of Medical Sciences, Yazd, Iran

${ }^{4}$ Children Growth Disorder Research Center, Shahid Sadoughi University of Medical Sciences, Yazd, Iran

${ }^{5}$ Department of Food Science and Technology, School of Public Health, Shahid Sadoughi University of Medical Sciences, Yazd, Iran

${ }^{6}$ Department of Medical Genetics, Shahid Sadoughi University of Medical Sciences, Yazd, Iran

7 Mother and Newborn Health Research Center, Shahid Sadoughi University of Medical Sciences, Yazd, Iran

* Corresponding author: Department of Surgery, Shahid Sadoughi University of Medical Sciences, Yazd, Iran; e-mail: niktabarsmn@gmail.com

Received: 21 February 2020

Accepted: 29 June 2020

Published online: 1 October 2020

Acta Medica (Hradec Králové) 2020; 63(3): 101-112

https://doi.org/10.14712/18059694.2020.27

(c) 2020 The Authors. This is an open-access article distributed under the terms of the Creative Commons Attribution License (http://creativecommons.org/licenses/by/4.0), which permits unrestricted use, distribution, and reproduction in any medium, provided the original author and source are credited. 


\section{INTRODUCTION}

Cutaneous malignant melanoma (CMM) is an aggressive tumor of melanocytes in skin with rapidly increasing incidence causing a major public health problem (1). CMM responsible for less than $5 \%$ of all skin cancers but over $75 \%$ of skin cancer related deaths (2-4). Its incidence varies dramatically between different ethnicities $(3,4)$. Analysis of the data from 29 countries suggested that Australia and New Zealand has by far the greatest incidence, illustrating the connection between white populations near the equator and CMM (4). There are numerous risk factors such as age, fair skin type, family history of CMM and presence of many or large nevi identified for developing CMM (5). It is firmly established that around $8-12 \%$ of CMM cases have a family history of CMM (6). UV-light is the most important cause, and the incidence of CMM in individuals with a susceptible skin type increases with proximity to the equator (7). Despite several decades of research on CMM, both etiology and pathogenesis of this disease is still unknown.

The etiology of CMM is likely to be multifactorial, involving UV exposure and genetic predisposition (6-8). The nucleotide excision repair (NER) is a versatile system that repairs a wide variety of DNA damage, including UV photoproducts (9). Thus, genetic mutations of NER proteins may be the natural candidate for development of CMM in association studies (10). There are at least eight core NER proteins participating in the pathway, and mutations in their genes may alter NER functions (11). The xeroderma pigmentosum complementation group C (XPC) is one of the key members in the NER pathway $(10,12)$. The XPC protein can form a XPC-RAD23B complex with RAD23B, which involved in global genome repair and works as the earliest damage detector to initiate the NER pathway. In addition, XPC may also possess some functions in base excision repair (BER) via attenuation with thymine DNA glycosylate and the human 8-oxoguanine DNA N-glycosylase 1 (hOGG1) $(13,14)$. Mutation in this gene can lead to Xeroderma pigmentosum (XP), a rare autosomal recessive disorder characterized by extreme UV-sensitivity (15).

The human XPC gene is located on chromosome 3p25.1, consists of 16 exons, and encodes a 940 amino acid protein (16). To date, at least 102 coding-region single nucleotide polymorphisms (SNPs) in the XPC gene have been identified, among which two common SNPs including Lys939Gln (rs2228001) in exon15 and Ala499Val (rs2228000) in exon 8 most frequently studied in CMM $(16,17)$. Moreover, it has been shown that XPC Lys939Gln and Ala499Val polymorphisms may be a risk factor in various cancers such as bladder cancer, prostate cancer, lung cancer, head and neck cancer and digestive system cancer (18-20). Over the last decade, several epidemiological studies evaluated association of XPC Lys939Gln and Ala499Val polymorphisms with risk of CMM. However, the associations remain controversial in susceptibility to CMM, partially because of a possible weak effect of the polymorphisms on CMM risk, ethnicity, sample size, study design, and also using different genotyping methods. Hence, we performed a meta-analysis to derive a relatively comprehensive assessment of the association between XPC Lys939Gln and Ala499Val polymorphisms and CMM risk.
MATERIALS AND METHODS

\section{CASE-CONTROL STUDY}

\section{Study Population}

The melanoma patient group consisted of 714 unselected participants, 451 women (mean age, 63 years) and 263 men (mean age, 65.5 years) from Poland.

The melanoma patient group consisted of 714 unselected participants, 451 women (mean age, 63 years) and 263 men (mean age, 65.5 years) from Poland.

A total of 150 cases diagnosed with CMM consisted of 150 participants included 83 women (mean age, 61 years) and 67 men (mean age, 63 years) were enrolled from central cities of Iran. All cases had undergone surgical treatment for primary (54\%) or metastatic melanoma (56\%) between June 2015 and July 2017. In addition, 150 age and sex matched, unrelated healthy subjects without cancer family history (first- and second-degree relatives) were recruited after dermatological examination form same cities. All participants were Persian. The study was approved by the Medical Research Ethics Committee and the written informed consent was obtained from the study participants.

\section{SNPs Genotyping}

DNA samples were obtained from peripheral blood of CMM cases and healthy subjects using the Qiagen Blood DNA Mini Kit (QIAGEN, Venlo, Netherlands) according to the instructions of the manufacturer. DNA was diluted to $50 \mathrm{ng} / \mu \mathrm{L}$ concentration and was stored at $-70^{\circ} \mathrm{C}$ until genotyping. Genotype analyses of XPC Lys939Gln and Ala499Val polymorphisms were performed by polymerase chain reaction-restriction fragment length polymorphism (PCR-RFLP) assay as described previously. Primer sequences were: XPC Lys939Gln, 5'-ACCTGTCCAGAGTGAGGCAG-3' (forward) and 5'-TCAAAGGGTGAGTGGGCTTT-3' (reverse), and XPC Ala499 Val, 5'TGGCCTCCAGGGTGTCTTAT-3' (forward) and 5'-ACTGTCAATGCCCACCACAT-3' (reverse). PCR amplification conditions included denaturation at $95{ }^{\circ} \mathrm{C}$ for 5 minutes, followed by 35 cycles of denaturation at $95^{\circ} \mathrm{C}$ for $30 \mathrm{sec}-$ onds, annealing at $67^{\circ} \mathrm{C}$ for 30 seconds, polymerization at $72{ }^{\circ} \mathrm{C}$ for 40 seconds, and a final stage of polymerization at $72{ }^{\circ} \mathrm{C}$ for 7 minutes. The PCR products were then digested with restriction endonucleases. For XPC Lys939Gln, the PCR products were with one unit of PvuII and AciI restriction enzymes for XPC Lys939Gln and Ala499Val overnight at $37^{\circ} \mathrm{C}$, respectively. DNA fragments were resolved on $3 \%$ agarose gels and stained with ethidium bromide. A difference between cases and controls regarding alleles and genotypes of XPC Lys939Gln and Ala499Val polymorphisms was analyzed by Chi-square test. Goodness-of-fit $\chi 2$ test was performed to test whether the genotype frequency distribution of each polymorphism in controls was in Hardy-Weinberg equilibrium (HWE). All statistical analysis was performed using SPSS version 20.0 (SPSS Inc., Chicago, IL, USA). A two-sided statistical significance level of 0.05 was chosen. 


\section{META-ANALYSIS}

\section{Search Strategy}

This meta-analysis conformed to the Preferred Reporting Items for Systematic Reviews and Meta-analyses (PRISMA) criteria. Eligible studies were identified through computer-aided literature searching in PubMed, EMBASE, Web of Science, Science Direct, Scopus, Cochrane Library database, Springer Link, Chinese Biomedical Database (CBD), China National Knowledge Infrastructure (CNKI), VIP, SID, Wanfang and Chinese Biomedical database up to September 25, 2019. The following terms and keywords were used for this search: "Skin Cancer" OR "Melanoma" OR "Cutaneous Melanoma" OR "Malignant Melanoma" OR "Cutaneous Malignant Melanoma") AND ("Xeroderma pigmentosum" OR "Complementation Group C" OR "XPC") AND ("Lys939Gln" OR "rs2228001") OR ("Ala499Val OR "rs2228000") AND (“Gene" OR "Polymorphism” OR "SNPs" OR "Mutation" OR "Variation" OR "Allele"). We also included additional studies by a hands-on search of references of original studies. Of the studies with the same or overlapping data, the most recent ones with the most subjects were selected.

\section{Selection Criteria}

The inclusion criteria of studies in the meta-analysis were defined as follows: 1) original and published data; 2) studies with case-control or cohort design; 3) evaluates the associations of XPC Lys939Gln and Ala499Val polymorphisms with CMM risk; 4) provides sufficient data for calculation of odds ratio (OR) with $95 \%$ confidence interval (CI). In addition, the following exclusion criteria were used: 1) nonecase control studies; 2) no usable data reported; 3) case only studies (without controls); 4) linkage studies, twins, sibling and other family based studies; 5) animal studies; 6) abstracts, case reports, posters, editorials, reviews, conference articles and previous meta-analyses; and 7) duplicated publications and repeated literatures.

\section{Data Extraction}

Two authors independently evaluated the articles for compliance with our inclusion criteria and data was carefully extracted from all eligible studies. Any potential disagreements were resolved by discussion until consensus was reached. The following data were extracted from each study: first author name, publication year, country of origin, ethnicity, source of controls, genotyping methods, genotype distribution of XPC Lys939Gln and Ala499Val polymorphisms in CMM cases and controls, minor allele frequencies (MAFs) in control groups, and result of HWE test in control subjects. Diverse ethnicity descents were categorized as Asian, Caucasian, and African. In the case of multiple studies by the same authors with overlapping data, the most recent published study with the largest number of participants was included in the current meta-analysis.

\section{STATISTICAL ANALYSIS}

The strength of the association between XPC Lys939Gln and Ala499Val polymorphisms and risk of CMM was measured by odd ratios (ORs) with $95 \%$ confidence intervals (CIs). Z-test was carried out to evaluate the statistical significance of pooled ORs. The pooled ORs were performed under the following five genetic models: allele model (B vs. A), homozygote model (BB vs. AA), heterozygote model (BA vs. AA), dominant model (BA+BB vs. $A A)$ and recessive model ( $\mathrm{BB}$ vs. $\mathrm{BA}+\mathrm{AA}$ ). The heterogeneity between studies was assessed with the chi-squared based $\mathrm{Q}$-test and $\mathrm{I}^{2}$ statistics. A significant $\mathrm{p}$ value $(<0.10)$ was used to indicate heterogeneity among studies. Moreover, a high value of $\mathrm{I}^{2}$ indicated a higher probability of the existence of heterogeneity $\left(\mathrm{I}^{2}=0 \%\right.$ to $25 \%$, no heterogeneity; $I^{2}=25 \%$ to $50 \%$, moderate heterogeneity; $I^{2}=50 \%$ to $75 \%$, large heterogeneity; and $\mathrm{I}^{2}=75 \%$ to $100 \%$, extreme heterogeneity). When between-study heterogeneity was found a random-effects model was performed; otherwise, a fixed-effects model (Mantel-Haenszel method) was accepted. Stratification and meta-regression analyses were used to detect the potential heterogeneity among studies. HWE of genotype distribution in the controls of included studies was conducted using an online program (http:// ihg2.helmholtz-muenchen.de/cgi-bin/hw/hwal.pl), and $\mathrm{P}<0.05$ was considered significantly deviating from HWE. To validate the reliability and stability of the results, sensitivity analysis was performed with a single study in the meta-analysis being deleted each time to reflect the influence of the individual data set on the pooled OR, as well as limiting this meta-analysis to studies which were conformed to HWE. Publication bias was assessed by Begg's test and Egger's test. The funnel plot was employed to examine the publication bias. Egger's regression analysis was used for reevaluation of publication bias. The significance of the intercept was determined by the $t$ test suggested by Egger, with $\mathrm{p}<0.10$ considered representative of statistically significant publication bias. Funnel plots and Egger's linear regression tests were used to provide a diagnosis of the potential publication bias. In the presence of a bias, we utilized the Duval and Tweedie non-parametric "trim and fill" methods to adjust results. All of the statistical calculations were performed using Comprehensive Meta-Analysis (CMA) software version 2.0 (Biostat, USA). Two-sided $\mathrm{P}$-values $<0.05$ were considered statistically significant.

\section{RESULTS}

\section{CASE-CONTROL STUDY}

In this case-control study, a total of 300 samples including 150 patients diagnosed with CMM and 150 controls were recruited. Age and gender did not show a statistically different distribution between cases and controls. All observed genotype frequencies of the XPC Lys939Gln and Ala499Val polymorphisms in the control group were in accordance with the HWE $(\mathrm{p}=0.492$ and $\mathrm{p}=0.698$, respectively). Distribution of XPC Lys939Gln and Ala499Val polymorphisms in melanoma cases and controls are shown in Table 1. The frequencies of XPC Lys939Gln polymorphism AA, AC, and CC genotypes in patients were $28.7 \%$, 
Tab. 1 Distribution of XPC gene polymorphisms in CMM cases and controls.

\begin{tabular}{|c|c|c|c|c|}
\hline Polymorphism & Cases $(n=150)$ & Control $(n=150)$ & OR $(95 \% \mathrm{CI})$ & p-value \\
\hline \multicolumn{5}{|l|}{ XPC Lys939Gln } \\
\hline \multicolumn{5}{|l|}{ Genotypes } \\
\hline AA & $55(28.7 \%)$ & $49(28.0 \%)$ & Ref. & \\
\hline$A C$ & $69(50.0 \%)$ & $77(53.3 \%)$ & $0.808(0.513-1.271)$ & 0.356 \\
\hline $\mathrm{CC}$ & $26(21.3 \%)$ & $24(18.7 \%)$ & $1.101(0.600-2.021)$ & 0.757 \\
\hline \multicolumn{5}{|l|}{ Allele } \\
\hline A & $179(53.7 \%)$ & $175(54.7 \%)$ & Ref. & \\
\hline C & $121(46.3 \%)$ & $125(45.3 \%)$ & $0.946(0.683-1.310)$ & 0.740 \\
\hline \multicolumn{5}{|l|}{ XPC Ala499Val } \\
\hline \multicolumn{5}{|l|}{ Genotypes } \\
\hline GG & $80(27.3 \%)$ & $79(31.3 \%)$ & Ref. & \\
\hline GA & $57(48.0 \%)$ & $61(46.0 \%)$ & $0.894(0.563-1.422)$ & 0.636 \\
\hline AA & $13(24.7 \%)$ & $10(22.7 \%)$ & $1.328(0.564-3.131)$ & 0.516 \\
\hline \multicolumn{5}{|l|}{ Allele } \\
\hline G & $217(51.3 \%)$ & $219(54.3 \%)$ & Ref. & \\
\hline A & $83(48.7 \%)$ & $81(46.7 \%)$ & $1.034(0.722-1.481)$ & 0.855 \\
\hline
\end{tabular}

OR: Odds Ratio; $\mathrm{Cl}$ : Confidence Interval

$50.0 \%$, and $21.3 \%$, respectively, which were similar to those in the control (28.1\%, 53.3\% and $18.6 \%$, respectively). For XPC Ala499Val polymorphism GG, GA and AA genotypes were found in $27.3 \%, 48.0 \%$ and $24.7 \%$ cases, respectively. In control group, GG, GA and AA genotypes were found in $31.3 \%, 46.0 \%$ and $22.7 \%$, respectively. The chi-square test results showed that there was no significant difference between the genotypic frequencies of XPC Lys939Gln and Ala499Val polymorphisms between CMM cases and controls (Table 1).

\section{META-ANALYSIS}

Figure 1 shows the flowchart of literature search and selection process. Based on the search criteria, 117 individual literatures were found. After screening the titles and abstracts, 45 publications were excluded. Therefore, 83 full text publications were preliminarily identified for further detailed evaluation. Subsequently, 68 studies were excluded: were not relevant to the XPC Lys939Gln and Ala499Val polymorphisms on CMM risk, not presenting sufficient data of genotype for calculating OR and 95\% CI, reviews, previous meta-analyses, and case reports. Finally, a total of 15 case-control studies including ten case-control studies with 5,990 cases and 7,697 controls on XPC Lys939Gln polymorphism and five case-control studies with 3,139 cases and 3,721 controls on XPC Ala499Val polymorphism were selected $(10,21-28)$. The baseline characteristics of the included studies are shown in Table 2 . The main characteristics of the studies were presented in Table 2.
All included studies were published between 2005 and 2013. The studies have been carried out in Germany, USA, Brazil, Spain, Poland, and Iran. As for ethnicity, eleven studies were conducted among Caucasians, two studies among Asians, two studies among Africans. Four different genotyping approaches were applied by the selected studies including: PCR-RFLP, TaqMan, Illumina GoldenGate Assay, and Sequenom. The genotype and minor allele frequency (MAF) distributions in the studies considered in the present meta-analysis are shown in Table 2. Moreover, the distribution of genotypes in the controls was in agreement with HWE for all selected studies, except for one study (23) on XPC Lys939Gln polymorphism (Table 2).

\section{QUANTITATIVE DATA SYNTHESIS}

\section{XPC Lys939GIn Polymorphism}

Table 3 listed the main results of the meta-analysis of XPC Lys939Gln polymorphism and CMM risk. Overall, after the ten case-control studies were pooled into meta-analysis, there was a significant association between XPC Lys939Gln polymorphism and risk of CMM under the recessive model (CC vs. CA+AA: OR = 1.108, 95\% CI 1.008-1.217; $\mathrm{P}=0.033$, Fig. $2 \mathrm{~A})$. The studies were further stratified by ethnicity and genotyping methods. Subgroup analysis by ethnicity showed that there was a significant association between XPC Lys939Gln polymorphism and CMM risk in mixed populations under all five genetic model, i.e., allele 
(C vs. A: OR = 1.543, 95\% CI 1.237-1.926, P $\leq 0.001$ ), homozygote (CC vs. AA: OR = 2.778, 95\% CI 1.691-4.563, P $\leq 0.001$ ), heterozygote (CA vs. AA: OR $=1.389,95 \%$ CI 1.005-1.920, $\mathrm{P}=0.046)$, dominant $(\mathrm{CC}+\mathrm{CA}$ vs. $\mathrm{AA}: \mathrm{OR}=1.574,95 \% \mathrm{CI}$ $0.158-2.140, P=0.004$ ), and recessive (CC vs. $C A+A A$ : OR $=2.246,95 \%$ CI 1.413-3.572, P = 0.001), but not in Caucasians. Moreover, in the PCR-RFLP group, significantly increased association between XPC Lys939Gln polymorphism and CMM risk was found under the recessive model (TT vs. TC+CC: OR = 1.297, 95\% CI 1.056-1.594, P = 0.013). However, no significant association was found in the TaqMan group (Table 3).

\section{XPC Ala499Val Polymorphism}

Table 4 listed the main results of the meta-analysis of XPC Ala499Val polymorphism and CMM risk. When all the eligible studies were pooled into the meta-analysis of XPC Ala499Val polymorphism was significantly increased risk of CMM was found under two genetic models i.e., allele (T vs. C: $\mathrm{OR}=0.918,95 \%$ CI 0.850-0.992; $\mathrm{P}=0.031$, Fig 2B) and dominant (TT+TC vs. CC: OR $=0.904,95 \%$ CI 0.819$0.997 ; \mathrm{P}=0.043)$. When stratified by ethnicity and genotyping method, no significant association was found in Caucasians and subgroup analysis by genotyping technique in PCR-RFLP and TaqMan subgroups (Table 4).

Tab. 2 Characteristics of studies included in the meta-analysis.

\begin{tabular}{|c|c|c|c|c|c|c|c|c|c|c|c|c|c|c|c|c|}
\hline \multirow{2}{*}{$\begin{array}{l}\text { First Au- } \\
\text { thor/ } \\
\text { Year }\end{array}$} & \multirow{2}{*}{$\begin{array}{l}\text { Country } \\
\text { (Ethnicity) }\end{array}$} & \multirow[t]{2}{*}{ SOC } & \multirow{2}{*}{$\begin{array}{l}\text { Genotyping } \\
\text { Technique }\end{array}$} & \multirow{3}{*}{$\begin{array}{l}\text { Case/ } \\
\text { Control }\end{array}$} & \multicolumn{5}{|c|}{ Cases } & \multicolumn{5}{|c|}{ Controls } & \multirow[t]{3}{*}{ MAFs } & \multirow[t]{3}{*}{ HWE } \\
\hline & & & & & \multicolumn{3}{|c|}{ Genotypes } & \multicolumn{2}{|l|}{ Allele } & \multicolumn{3}{|c|}{ Genotypes } & \multicolumn{2}{|c|}{ Allele } & & \\
\hline \multicolumn{4}{|c|}{ XPC Lys939Gln } & & AA & AC & CC & A & C & AA & AC & CC & A & C & & \\
\hline $\begin{array}{l}\text { Blankenburg } \\
2005\end{array}$ & $\begin{array}{l}\text { Germany } \\
\text { (Caucasian) }\end{array}$ & PB & PCR-RFLP & $294 / 373$ & 113 & 128 & 53 & 354 & 234 & 138 & 185 & 50 & 461 & 285 & 0.382 & 0.330 \\
\hline $\begin{array}{l}\mathrm{Li} \\
2006\end{array}$ & $\begin{array}{l}\text { USA } \\
\text { (Caucasian) }\end{array}$ & PB & PCR-RFLP & $602 / 603$ & 223 & 281 & 98 & 727 & 477 & 195 & 311 & 97 & 701 & 505 & 0.418 & 0.144 \\
\hline $\begin{array}{l}\text { Millikan } \\
2006\end{array}$ & $\begin{array}{l}\text { USA } \\
\text { (Caucasian) }\end{array}$ & PB & TaqMan & $1209 / 2439$ & 409 & 580 & 220 & 1398 & 1020 & 785 & 1252 & 402 & 2822 & 2056 & 0.421 & $\begin{array}{l}\leq \\
0.001\end{array}$ \\
\hline \begin{tabular}{|l} 
Figl \\
2010
\end{tabular} & $\begin{array}{l}\text { Germany } \\
\text { (Caucasian) }\end{array}$ & PB & TaqMan & $1185 / 1273$ & 420 & 568 & 197 & 1408 & 962 & 460 & 597 & 216 & 1517 & 1029 & 0.404 & 0.348 \\
\hline $\begin{array}{l}\text { Goncalves } \\
2011\end{array}$ & $\begin{array}{l}\text { Brazil } \\
\text { (Mixed) }\end{array}$ & HB & PCR-RFLP & $192 / 205$ & 61 & 93 & 38 & 215 & 169 & 102 & 85 & 21 & 289 & 127 & 0.305 & 0.597 \\
\hline $\begin{array}{l}\text { Ibarrola- } \\
\text { Villava } 2011\end{array}$ & $\begin{array}{l}\text { Spain } \\
\text { (Caucasian) }\end{array}$ & PB & TaqMan & $684 / 406$ & 281 & 289 & 114 & 851 & 517 & 154 & 198 & 54 & 506 & 306 & 0.376 & 0.439 \\
\hline $\begin{array}{l}\text { Paszkowska- } \\
\text { Szczur } 2013\end{array}$ & $\begin{array}{l}\text { Poland } \\
\text { (Caucasian) }\end{array}$ & PB & Sequenom & $635 / 1336$ & 227 & 314 & 94 & 768 & 502 & 480 & 647 & 209 & 1607 & 1065 & 0.398 & 0.711 \\
\hline $\begin{array}{l}\text { Oliveira } \\
2013\end{array}$ & $\begin{array}{l}\text { Brazil } \\
\text { (Mixed) }\end{array}$ & HB & PCR-RFLP & $146 / 146$ & 59 & 65 & 22 & 183 & 109 & 64 & 72 & 10 & 200 & 92 & 0.315 & 0.084 \\
\hline $\begin{array}{l}\text { Torres } \\
2013\end{array}$ & $\begin{array}{l}\text { USA } \\
\text { (Caucasian) }\end{array}$ & PB & IGGA & $893 / 766$ & 304 & 451 & 138 & 1059 & 727 & 273 & 382 & 111 & 928 & 604 & 0.394 & 0.222 \\
\hline $\begin{array}{l}\text { Present } \\
\text { study }\end{array}$ & $\begin{array}{l}\text { Iran } \\
\text { (Asian) }\end{array}$ & PB & PCR-RFLP & $150 / 150$ & 55 & 69 & 26 & 179 & 121 & 49 & 77 & 24 & 175 & 125 & 0.416 & 0.492 \\
\hline \multicolumn{5}{|c|}{ XPC Ala499Val } & CC & CT & TT & C & $\mathbf{T}$ & CC & CT & TT & C & $\mathbf{T}$ & & \\
\hline Li 2006 & $\begin{array}{l}\text { USA } \\
\text { (Caucasian) }\end{array}$ & PB & PCR-RFLP & $602 / 603$ & 338 & 214 & 50 & 890 & 314 & 318 & 248 & 37 & 881 & 322 & 0.267 & 0.212 \\
\hline Figl 2010 & $\begin{array}{l}\text { Germany } \\
\text { (Caucasian) }\end{array}$ & PB & TaqMan & $1184 / 1274$ & 626 & 477 & 81 & 1729 & 639 & 670 & 516 & 88 & 1856 & 692 & 0.271 & 0.397 \\
\hline $\begin{array}{l}\text { Ibarrola- } \\
\text { Villava } 2011\end{array}$ & $\begin{array}{l}\text { Spain } \\
\text { (Caucasian) }\end{array}$ & PB & TaqMan & $684 / 406$ & 408 & 227 & 49 & 1043 & 325 & 225 & 158 & 23 & 608 & 204 & 0.251 & 0.488 \\
\hline $\begin{array}{l}\text { Paszkowska- } \\
\text { Szczur } 2013\end{array}$ & $\begin{array}{l}\text { Poland } \\
\text { (Caucasian) }\end{array}$ & PB & Sequenom & $519 / 1288$ & 245 & 240 & 34 & 730 & 308 & 548 & 563 & 177 & 1659 & 917 & 0.356 & 0.093 \\
\hline $\begin{array}{l}\text { Present } \\
\text { study }\end{array}$ & $\begin{array}{l}\text { Iran } \\
\text { (Asian) }\end{array}$ & PB & PCR-RFLP & $150 / 150$ & 80 & 57 & 13 & 217 & 83 & 79 & 61 & 10 & 219 & 81 & 0.270 & 0.698 \\
\hline
\end{tabular}


NEITY AND SENSITIVITY ANALYSIS

As shown in Table 3, significant between-study heterogeneity appeared under four genetic models except under recessive model for overall analysis, thus, we have utilized a random-effect model to calculate the pooled estimates. Moderate between-study heterogeneity were observed in the overall analysis evaluating the association between XPC Lys939Gln polymorphism and CMM under four genetic models, i.e., allele $\left(\mathrm{I}^{2}=50.18 \%\right.$ and $\left.\mathrm{P}_{\mathrm{H}}=0.034\right)$, homozygote $\left(\mathrm{I}^{2}=48.81 \%\right.$ and $\left.\mathrm{P}_{\mathrm{H}}=0.040\right)$, heterozygote $\left(\mathrm{I}^{2}=64.42 \%\right.$ and $\left.\mathrm{P}_{\mathrm{H}}=0.003\right)$, and dominant $\left(\mathrm{I}^{2}=48.78 \%\right.$ and $\mathrm{P}_{\mathrm{H}}=0.040$ ). To the XPC Ala499Val polymorphism, a significant between-study heterogeneity were observed among overall studies in the two genetic models, i.e., the homozygote model $\left(\mathrm{I}^{2}=47.33 \%\right.$ and $\left.\mathrm{P}_{\mathrm{H}}=0.002\right)$ and recessive model $\left(\mathrm{I}^{2}=80.15 \%\right.$ and $\left.\mathrm{P}_{\mathrm{H}} \leq 0.001\right)$. In addition, we have performed leave-one-out sensitivity analysis validated the stability of results that no single study changed the pooled ORs qualitatively (data not shown). However, the pooled ORs of XPC Lys939Gln and Ala499Val polymorphisms were not influenced by sequentially removing individual studies, suggesting that the included studies to this meta-analysis were statistically accurate.

\section{PUBLICATION BIAS}

We have used both Begg's funnel plot and Egger's test to assess the publication bias of literatures. The results of Egger's regression test and relative asymmetry of funnel plot provided sufficient evidence for publication bias for

Tab. 3 Summary of meta-analysis for the association of XPC Lys939Gln polymorphism with risk of CMM.

\begin{tabular}{|c|c|c|c|c|c|c|c|c|c|c|}
\hline \multirow[t]{2}{*}{ Subgroup } & \multirow[t]{2}{*}{ Genetic Model } & \multirow{2}{*}{$\begin{array}{l}\text { Type } \\
\text { of Model }\end{array}$} & \multicolumn{2}{|c|}{ Heterogeneity } & \multicolumn{4}{|c|}{ Odds Ratio } & \multicolumn{2}{|c|}{ Publication Bias } \\
\hline & & & $I^{2}(\%)$ & $P_{H}$ & OR & $95 \% \mathrm{Cl}$ & $Z_{\text {test }}$ & $P_{\text {OR }}$ & $P_{\text {Beggs }}$ & $P_{\text {Eggers }}$ \\
\hline \multirow[t]{5}{*}{ Overall } & C vs. A & Random & 50.18 & 0.034 & 1.040 & $0.963-1.123$ & 1.010 & 0.312 & 0.152 & 0.124 \\
\hline & CC vs. AA & Random & 48.81 & 0.040 & 1.127 & $0.961-1.322$ & 1.472 & 0.141 & 0.107 & 0.046 \\
\hline & CA vs. AA & Random & 64.42 & 0.003 & 0.934 & $0.812-1.074$ & -0.955 & 0.339 & 0.591 & 0.650 \\
\hline & $C C+C A$ vs. $A A$ & Random & 48.78 & 0.040 & 0.998 & $0.895-1.113$ & -0.039 & 0.969 & 0.720 & 0.417 \\
\hline & $C C$ vs. $C A+A A$ & Fixed & 7.78 & 0.107 & 1.108 & $1.008-1.217$ & 2.128 & 0.033 & 0.049 & 0.024 \\
\hline \multicolumn{11}{|l|}{ Ethnicity } \\
\hline \multirow[t]{5}{*}{ Caucasians } & Cvs. A & Fixed & 0.00 & 0.897 & 1.002 & $0.951-1.055$ & 0.069 & 0.945 & 0.763 & 0.923 \\
\hline & CC vs. AA & Fixed & 0.00 & 0.839 & 1.035 & $0.929-1.153$ & 0.630 & 0.529 & 0.367 & 0.450 \\
\hline & CA vs. AA & Fixed & 18.60 & 0.288 & 0.939 & $0.867-1.016$ & -1.563 & 0.118 & 0.548 & 0.359 \\
\hline & $C C+C A$ vs. $A A$ & Fixed & 0.00 & 0.581 & 0.962 & $0.893-1.037$ & -1.006 & 0.315 & 0.763 & 0.497 \\
\hline & $C C$ vs. $C A+A A$ & Fixed & 0.00 & 0.531 & 1.074 & $0.974-1.984$ & 1.433 & 0.152 & 0.229 & 0.321 \\
\hline \multicolumn{11}{|l|}{ Genotyping } \\
\hline \multirow[t]{5}{*}{ Mixed } & C vs. A & Fixed & 42.50 & 0.187 & 1.543 & $1.237-1.926$ & 3.840 & $\leq 0.001$ & NA & NA \\
\hline & CC vs. AA & Fixed & 0.00 & 0.653 & 2.778 & $1.691-4.563$ & 4.036 & $\leq 0.001$ & NA & NA \\
\hline & CA vs. AA & Fixed & 71.69 & 0.060 & 1.389 & $1.005-1.920$ & 1.991 & 0.046 & NA & NA \\
\hline & $C C+C A$ vs. $A A$ & Fixed & 67.64 & 0.079 & 1.574 & $0.158-2.140$ & 2.895 & 0.004 & NA & NA \\
\hline & $C C$ vs. $C A+A A$ & Fixed & 0.00 & 0.825 & 2.246 & $1.413-3.572$ & 3.420 & 0.001 & NA & NA \\
\hline \multirow[t]{5}{*}{ PCR-RFLP } & C vs. A & Random & 75.85 & 0.002 & 1.143 & $0.906-1.442$ & 1.130 & 0.259 & 0.462 & 0.255 \\
\hline & CC vs. AA & Random & 72.84 & 0.005 & 1.441 & $0.901-2.305$ & 1.524 & 0.127 & 0.462 & 0.185 \\
\hline & CA vs. AA & Random & 79.46 & 0.001 & 0.876 & $0.595-1.291$ & -0.667 & 0.504 & 1.000 & 0.995 \\
\hline & $C C+C A$ vs. $A A$ & Random & 73.47 & 0.005 & 1.065 & $0.777-1.461$ & 0.339 & 0.694 & 0.806 & 0.346 \\
\hline & $C C$ vs. $C A+A A$ & Fixed & 52.18 & 0.079 & 1.297 & $1.056-1.594$ & 2.482 & 0.013 & 0.462 & 0.125 \\
\hline \multirow[t]{5}{*}{ TaqMan } & C vs. A & Fixed & 0.00 & 0.996 & 1.000 & 0.941-1.064 & 0.013 & 0.990 & 1.000 & 0.796 \\
\hline & CC vs. AA & Fixed & 0.00 & 0.861 & 1.026 & $0.903-1.166$ & 0.398 & 0.691 & 1.000 & 0.727 \\
\hline & CA vs. AA & Fixed & 22.90 & 0.273 & 0.947 & 0.861-1.041 & -1.130 & 0.258 & 0.734 & 0.732 \\
\hline & $C C+C A$ vs. $A A$ & Fixed & 0.00 & 0.654 & 0.967 & $0.884-1.057$ & -0.745 & 0.456 & 0.734 & 0.743 \\
\hline & $C C$ vs. $C A+A A$ & Fixed & 6.609 & 0.360 & 1.059 & $0.944-1.189$ & 0.979 & 0.328 & 1.000 & 0.800 \\
\hline
\end{tabular}

NA: Not Applicable 
XPC Lys939Gln in the homozygote model $\left(\mathrm{P}_{\text {Begg's }}=0.107\right.$, $\mathrm{P}_{\text {Eggers }}=0.046$, Fig. $\left.3 \mathrm{~A}\right)$ and the recessive model $\left(\mathrm{P}_{\text {Begg's }}=0.049\right.$, $\mathrm{P}_{\text {Eggers }}=0.024$, Fig. 3B), suggesting that there was obvious publication bias in the genetic contrast. Therefore, we have performed the Duval and Tweedie nonparametric "trim and fill" method to adjust for publication bias. The "trim and fill" method did not change conclusion, indicating the results were statistically robust. Moreover, there was no publication bias of literatures for XPC Lys939Gln polymorphism by subgroup analyses (Table 3 ). To the XPC Ala499Val polymorphism, the shapes of the funnel plots and Egger's test revealed no obvious asymmetry for association in the overall and by subgroup analyses (Table 3 ).

\section{MINOR ALLELE FREQUENCIES (MAFS)}

The minor allele frequencies (MAFs) of the XPC Lys939Gln and Ala499Val polymorphisms by ethnicity are presented in Tables 2 . The XPC 939Gln allele frequencies in the overall, Caucasian and mixed populations were $36.30 \%$
(30.50-42.10\%), 39.85\% (37.60-42.10\%), and 31.0\% (30.50$31.50 \%)$, respectively. The XPC $499 \mathrm{Val}$ allele frequency in the overall population was $30.35 \%$ (25.10-35.60\%). Therefore, the frequencies of the XPC 939Gln allele in Caucasians were greater than overall and mixed populations.

\section{DISCUSSION}

Our case-control study showed that there was no a significant association between XPC Lys939Gln and Ala499Val polymorphisms and an increased risk of CMM in our population. One limitation was the relatively small sample size to establish an association between polymorphisms at XPC gene and risk of CMM. Similarly, three studies by Ibarrola-Villava et al., Li et al., and Blankenburg et al., with large sample size did not find an association between the XPC Val499Ala polymorphism on melanoma risk (21, 22, 26). However, Paszkowska-Szczur et al., in case-control study with 714 unselected melanoma patients and 1,841

Tab. 4 Summary of meta-analysis for the association of XPC Ala499Val polymorphism with risk of CMM.

\begin{tabular}{|c|c|c|c|c|c|c|c|c|c|c|}
\hline \multirow[t]{2}{*}{ Subgroup } & \multirow[t]{2}{*}{ Genetic Model } & \multirow{2}{*}{$\begin{array}{l}\text { Type } \\
\text { of Model }\end{array}$} & \multicolumn{2}{|c|}{ Heterogeneity } & \multicolumn{4}{|c|}{ Odds Ratio } & \multicolumn{2}{|c|}{ Publication Bias } \\
\hline & & & $I^{2}(\%)$ & $\mathbf{P}_{\mathrm{H}}$ & OR & $95 \% \mathrm{Cl}$ & $Z_{\text {test }}$ & $P_{O R}$ & $P_{\text {Beggs }}$ & $\mathbf{P}_{\text {Eggers }}$ \\
\hline \multirow[t]{5}{*}{ Overall } & T vs. C & Fixed & 47.33 & 0.108 & 0.918 & $0.850-0.992$ & -2.157 & 0.031 & 1.000 & 0.865 \\
\hline & TT vs. CC & Random & 77.08 & 0.002 & 0.926 & $0.598-1.434$ & -0.346 & 0.729 & 1.000 & 0.646 \\
\hline & TT vs. CC & Fixed & 0.00 & 0.535 & 0.911 & $0.822-1.009$ & -1.786 & 0.074 & 0.220 & 0.426 \\
\hline & TT+TC vs. CC & Fixed & 0.00 & 0.652 & 0.904 & 0.819-0.997 & -2.028 & 0.043 & 1.000 & 0.657 \\
\hline & TT vs. TC+CC & Random & 80.15 & $\leq 0.001$ & 0.973 & $0.616-1.536$ & -0.117 & 0.906 & 0.806 & 0.590 \\
\hline \multicolumn{11}{|l|}{ Ethnicity } \\
\hline \multirow[t]{5}{*}{ Caucasians } & T vs. C & Fixed & 58.07 & 0.067 & 0.913 & $0.844-0.988$ & -2.249 & 0.024 & 0.734 & 0.816 \\
\hline & TT vs. CC & Random & 82.03 & 0.001 & 0.882 & $0.541-1.439$ & -0.502 & 0.616 & 0.734 & 0.800 \\
\hline & TT vs. CC & Fixed & 4.27 & 0.371 & 0.910 & $0.820-1.011$ & -1.756 & 0.079 & 0.089 & 0.077 \\
\hline & TT+TC vs. CC & Fixed & 0.00 & 0.503 & 0.900 & $0.814-0.995$ & -2.051 & 0.040 & 0.734 & 0.135 \\
\hline & TT vs. $\mathrm{TC}+\mathrm{CC}$ & Random & 84.49 & $\leq 0.001$ & 0.927 & $0.555-1.547$ & -0.289 & 0.772 & 0.734 & 0.704 \\
\hline \multicolumn{11}{|l|}{ Genotyping } \\
\hline \multirow[t]{5}{*}{ PCR-RFLP } & T vs. C & Fixed & 0.00 & 0.750 & 0.980 & $0.835-1.154$ & -0.226 & 0.821 & NA & NA \\
\hline & TT vs. CC & Fixed & 0.00 & 0.985 & 1.274 & $0.852-1.904$ & 1.180 & 0.238 & NA & NA \\
\hline & TT vs. CC & Fixed & 0.00 & 0.638 & 0.833 & $0.673-1.031$ & -1.680 & 0.093 & NA & NA \\
\hline & TT+TC vs. CC & Fixed & 0.00 & 0.669 & 0.891 & $0.727-1.091$ & -1.114 & 0.265 & NA & NA \\
\hline & TT vs. TC+CC & Fixed & 0.00 & 0.932 & 1.373 & $0.928-2.033$ & 1.586 & 0.113 & NA & NA \\
\hline \multirow[t]{5}{*}{ TaqMan } & T vs. C & Fixed & 0.00 & 0.591 & 0.973 & $0.875-1.083$ & -0.497 & 0.619 & NA & NA \\
\hline & TT vs. CC & Fixed & 0.00 & 0.573 & 1.034 & $0.787-1.359$ & 0.240 & 0.811 & NA & NA \\
\hline & TT vs. CC & Fixed & 49.84 & 0.158 & 0.928 & $0.807-1.067$ & -1.047 & 0.295 & NA & NA \\
\hline & TT+TC vs. CC & Fixed & 13.93 & 0.281 & 0.943 & $0.826-1.078$ & -0.854 & 0.393 & NA & NA \\
\hline & TT vs. $T C+C C$ & Fixed & 0.00 & 0.393 & 1.603 & $0.814-1.388$ & 0.446 & 0.656 & NA & NA \\
\hline
\end{tabular}

NA: Not Applicable. 
controls demonstrated that XPC Val499Ala polymorphism at XPC gene is associated with melanoma susceptibility in the polish population, but not XPC Lys939Gln polymorphism (10).

In the present meta-analysis, a total of ten studies with 5,990 cases and 7,697 controls were retrieved on XPC Lys$939 \mathrm{Gln}$ polymorphism. Our pooled analysis showed that the XPC Lys939Gln polymorphism was significantly associated with increased risk of CMM. Our results were inconsistent with the previous meta-analyses showed that the XPC Lys939Gln polymorphism might be associated with risk of CMM. In 2013, Zhou et al., in a meta-analysis of seven studies (with 3,971 cases and 5,873 controls) have reported that the XPC Lys939Gln polymorphism was not significantly associated with CMM risk under all five genetic models (29). Jiang et al., in a more recently published meta-analysis with eight studies of 4,631 cases and 5,111 controls have found also negative results (30). The current meta-analysis has a number of strengths when compared to the previous meta-analyses. We have evaluated the association of XPC Lys939Gln polymorphism with CMM with the largest sample size to date. We expanded sample size by adding two more studies and our case-control study data and improved statistical power to derive a more precise risk estimate for the associations. Remarkably, the both previous meta-analyses did not report the significant association between XPC Lys939Gln and risk of CMM. Therefore, the positive results of the current meta-analysis might have been caused by large sample size.

\section{Pर्IS ME \\ PRISMA 2009 Flow Diagram}

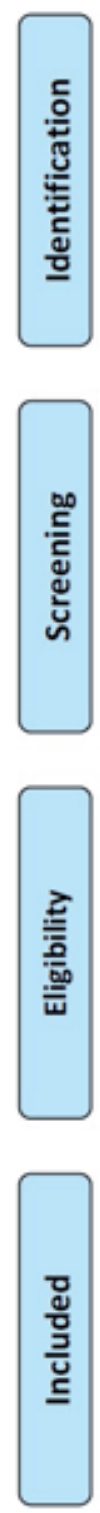

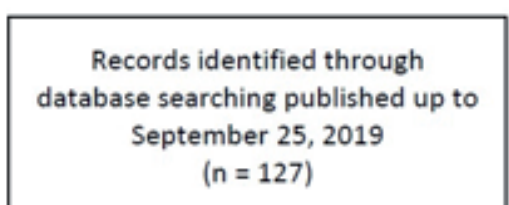

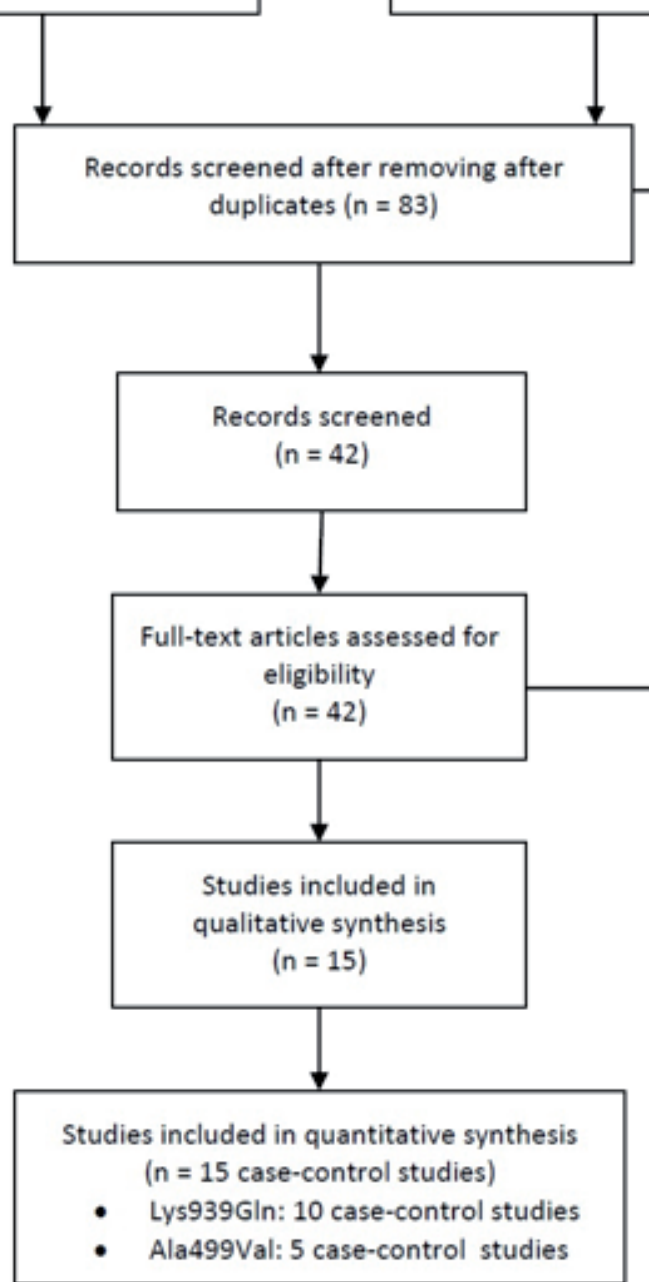

Additional records identified

through other sources published up to September 25, 2019 ( $n=1)$

Full-text articles excluded, with reasons $(n=27)$ Review, case reports, letters to editors, evaluated other diseases instead of CMM, not relevant to the XPC Lys939GIn and Ala499Val SNPs.

Fig. 1 Flowchart of literature search and selection process. 
A

\begin{tabular}{|c|c|c|c|c|c|c|c|c|}
\hline \multirow[t]{2}{*}{ Study name } & \multicolumn{5}{|c|}{ Statistics for each study } & & \multicolumn{2}{|l|}{ Odds ratio and $95 \% \mathrm{Cl}$} \\
\hline & $\begin{array}{c}\text { Odds } \\
\text { ratio }\end{array}$ & $\begin{array}{l}\text { Lower } \\
\text { limit }\end{array}$ & $\begin{array}{l}\text { Upper } \\
\text { limit }\end{array}$ & Z-Value & p-Value & & & $\begin{array}{l}\text { Relative } \\
\text { weight }\end{array}$ \\
\hline Blankenburg 2005 & 1.421 & 0.933 & 2.164 & 1.635 & 0.102 & & & 5.01 \\
\hline Li 2006 & 1.014 & 0.746 & 1.378 & 0.091 & 0.928 & & & 9.45 \\
\hline Millikan 2006 & 1.127 & 0.940 & 1.351 & 1.296 & 0.195 & & & 27.09 \\
\hline Figl 2010 & 0.976 & 0.790 & 1.206 & -0.227 & 0.820 & & & 19.82 \\
\hline Goncalves 2011 & 2.162 & 1.217 & 3.840 & 2.631 & 0.009 & & & 2.69 \\
\hline Ibarrola-Villava 2011 & 1.304 & 0.919 & 1.850 & 1.485 & 0.137 & & & 7.25 \\
\hline Paszkowska-Szczur 2013 & 30.937 & 0.719 & 1.220 & -0.483 & 0.629 & & & 12.73 \\
\hline Oliveira 2013 & 2.413 & 1.099 & 5.296 & 2.196 & 0.028 & & & 1.44 \\
\hline Torres 2013 & 1.079 & 0.823 & 1.414 & 0.547 & 0.584 & & & 12.10 \\
\hline \multirow[t]{3}{*}{ Niktabar 2018} & 1.101 & 0.600 & 2.021 & 0.310 & 0.757 & & & 2.41 \\
\hline & 1.108 & 1.008 & 1.217 & 2.128 & 0.033 & & & \\
\hline & & & & & & 0.01 & 0.1 & \\
\hline
\end{tabular}

B

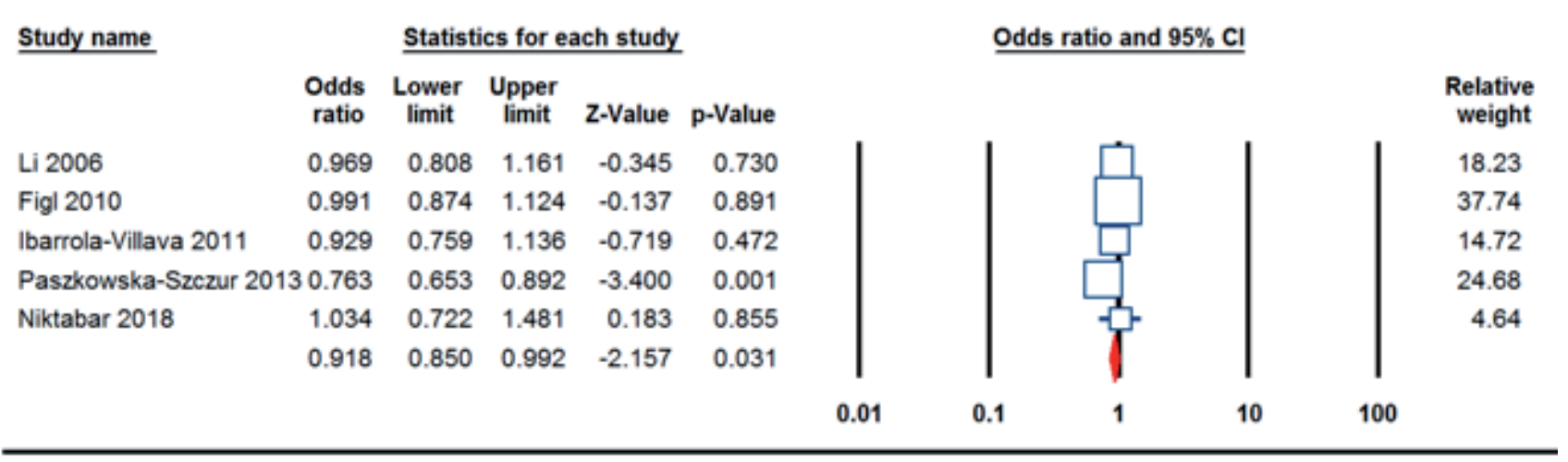

Fig. 2 Forest plots for association between XPC Lys939Gln and Ala499Val polymorphisms and CM risk. A: XPC Lys939Gln (recessive model: CC vs. $(A+A A)$ ) B: XPC Ala499Val (allele model: T vs. C).

The XPC Ala499Val polymorphism is one of the more widely studied SNPs in the XPC gene involving a substitution of alanine for valine (31). Mutations of the XPC genes may increase malignancy susceptibility by causing a severe depression of NER and consequently altering DNA repair activity (32). However, the exact consequences of the Ala499Val substitution on protein function or structure not well established (33). In the current meta-analysis based on five case-control studies with 3,139 CMM cases and 3,721 controls we evaluated the association of XPC Ala499Val polymorphism with CMM. Overall, we found that there was a significant association between XPC Ala499Val and increased risk of CMM under two genetic models i.e., allele ( $\mathrm{T}$ vs. C: OR $=0.918,95 \%$ CI $0.850-0.992$; $\mathrm{P}=0.031$ ) and dominant (TT+TC vs. CC: $\mathrm{OR}=0.904,95 \%$ CI 0.819-0.997; $\mathrm{P}=0.043$ ). In recent years, several meta-analyses have investigated the role XPC Ala499Val in susceptibility to different human malignancies. Interestingly, those meta-analyses results showed that the XPC Ala499Val polymorphism was not associated with increased risk of most tumors including breast, colorectal, gastric, and lung. However, their results demonstrated that the XPC Ala499Val polymorphism may contribute to susceptibility to bladder cancer, especially among Caucasians $(33,34)$. Moreover, our pooled results showed that this polymorphism is significantly associated with risk of CMM.

Between-study heterogeneity is a potential problem in genetic association meta-analysis studies that may affect the interpretation of the pooled results (35-37). It may be due to various factors, such as diversity in the population characteristics (ethnicity, age, and sun exposure), differences in the number of cases and controls, diverse genotype distribution of XPC gene polymorphisms in different ethnicities, using different genotyping methods and study design (38-41). In the present meta-analysis we found relatively high heterogeneity in overall analysis. However, after subgroup analyses by ethnicity, source of controls and genotyping method, the between studies heterogeneity was removed or significantly decreased. Thus, subgroup analyses showed that the origin of the heterogeneity among the studies was ethnicity and genotyping methods.

The current meta-analysis has some advantages. First, to the best of our knowledge, this was the first meta-analysis to evaluate the association between XPC Ala499Val polymorphism and CMM risk. Second, in the current meta-analysis, more studies were included than previous meta-analyses on XPC Lys939Gln polymorphism association with CMM. Third, we have performed sensitive analysis by excluding studies deviating from HWE, due that 
deviations from HWE in healthy subjects may be a sign of selection bias. However, the pooled ORs did not significantly influenced, suggesting that the included studies to this meta-analysis were statistically accurate. Fourth, compared with the previous meta-analysis, subgroup analysis by ethnicity and genotyping methods were also carried out.

Despite of the advantages mentioned above, there were still several limitations that should be noted in the meta-analysis. First, although we were able to discern a significant association of XPC Lys939Gln and Ala499Val polymorphisms with CMM in the overall population, the sample size was still relatively small. Second, the included studies involved in the meta-analysis were mainly were performed among Caucasian populations, so it is uncertain whether these results are generalizable to other ethnicities. Thus, to strengthening the statistical power will require more data from different ethnicities. Third, we have included only English published studies in this meta-analysis, which might have led to literature biases. Fourth, although we have performed a comprehensive search to identify all eligible case-control studies and included our unpublished original data, some relevant studies with negative results might be still missed, which might have led to literature biases. Fifth, there was significant between-study heterogeneity for XPC Lys939Gln polymorphism under four genetic models and for XPC Ala499Val under two genetic models. Even though the random-effects model was used to calculate pool ORs, the precision of outcome might be affected. Sixth, the lack of available data prevented an adjustment for subgroup factors such as age, gender, exposure to environmental risk
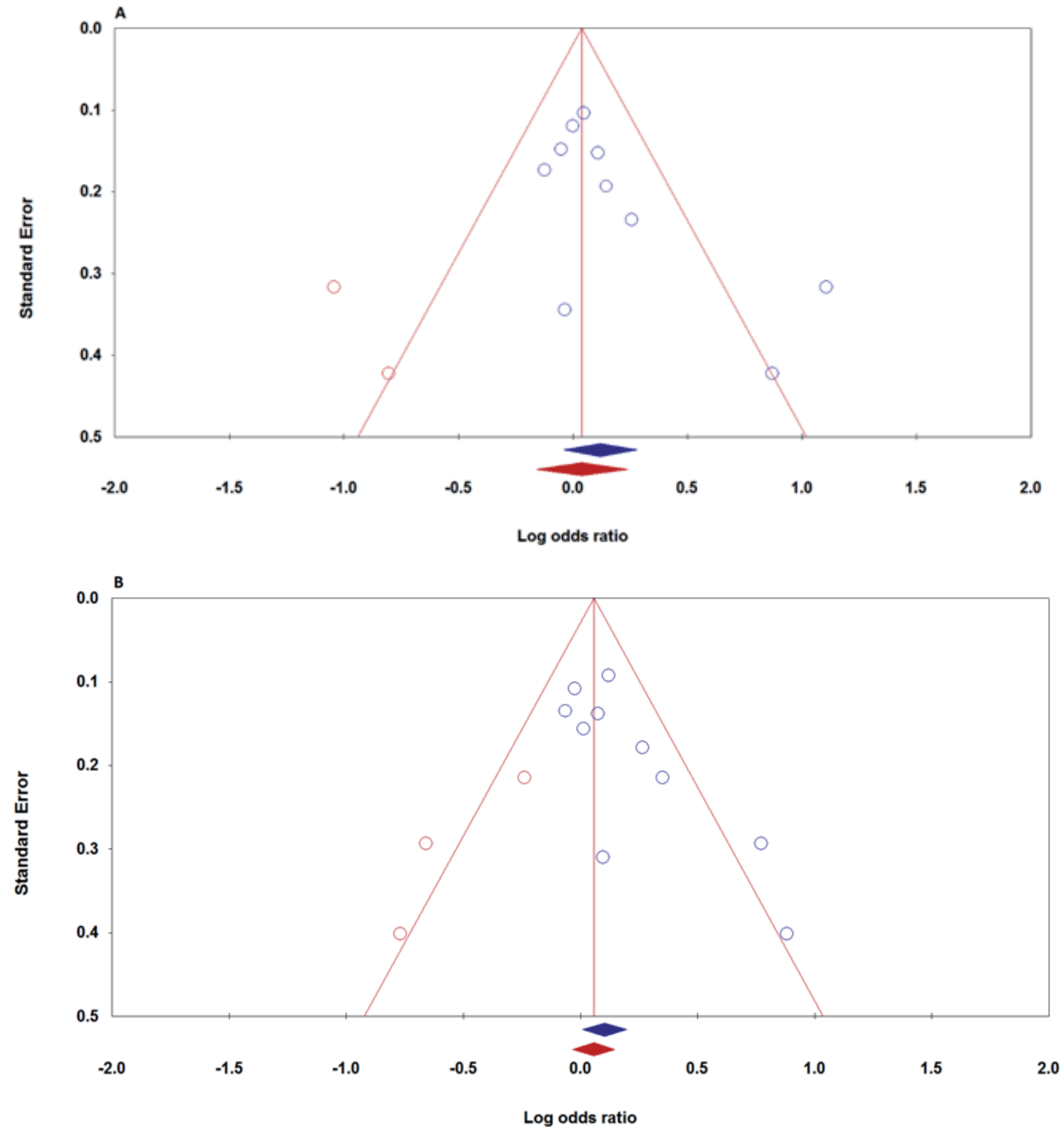

Fig. 3 Begg's funnel plot of publication bias test for association between XPC Lys939Gln polymorphism and CM risk before (blue) and after (red) trim-and-fill method. A: homozygote model (CC vs. AA); B: recessive model (CC vs. CA+AA). 
factors, lifestyle and other confounding factors that can interact with genetic factors to influence the association of XPC Lys939Gln and Ala499Val polymorphisms with susceptibility to CMM. Finally, lack of original data from included studies limited our results because the interactions between gene- gene, gene -environment, and also XPC Lys939Gln/Ala499Val may be modulated the association of XPC Lys939Gln and Ala499Val polymorphisms on development of CMM.

In summary, our results demonstrated that the Lys939Gln and Ala499Val polymorphisms at XPC gene were significantly associated with an increased risk of CMM in the global population. Moreover, stratified analysis by ethnicity revealed that XPC Ala499Val and Lys939Gln polymorphisms were significantly associated with risk of CMM in Caucasians and mixed populations, respectively. Thus, these polymorphisms may serve as genetic biomarker for development of CMM. However, considering the limitations mentioned above, more well-designed studies with larger sample sizes are needed in future.

\section{ACKNOWLEDGEMENTS}

The authors thank Ms. Sahel Khajehnoori and Mrs. Elham Akbarian (who is currently working in the Mother \& Newborn Health Research Center and Children Growth Disorder Research Center at Shahid Sadoughi University of Medical Sciences, respectively) for her help in revising the grammar issue of this manuscript.

\section{COMPETING INTERESTS}

The authors declare that there are no competing interests associated with the manuscript.

\section{FUNDING}

Not applicable.

\section{ABBREVIATIONS}

XPC: Xeroderma Pigmentosum Complementation Group C

CMM: Cutaneous Malignant Melanoma

ORs: Odds Ratios

CIs: $\quad$ Confidence Intervals

NER: $\quad$ Nucleotide Excision Repair

BER: $\quad$ Base Excision Repair

hOGG1: human 8-oxoguanine DNA N-glycosylase 1

XP: $\quad$ Xeroderma Pigmentosum

HWE: Hardy-Weinberg Equilibrium

PRISMA: Preferred Reporting Items for Systematic

Reviews and Meta-analyses

MAFs: Minor Allele Frequencies

CMA: Comprehensive Meta-Analysis

SOC: $\quad$ Source of Control

PB: $\quad$ Population Based
$\mathrm{HB}$ :

IGGA: hospital Based

RFLP: Illumina GoldenGate Assay Restriction Fragment Length Polymorphism

\section{REFERENCES}

1. Situm M, Buljan M, Kolić M, Vučić M. Melanoma-clinical, dermatoscopical, and histopathological morphological characteristics. Acta Dermatovenerologica Croatica: ADC 2014; 22: 1-12.

2. Erdei E, Torres SM. A new understanding in the epidemiology of melanoma. Expert Review of Anticancer Therapy 2010; 10: 1811-23.

3. Wu S, Han J, Song F, et al. Caffeine Intake, Coffee Consumption, and Risk of Cutaneous Malignant Melanoma. Epidemiology 2015; 26: 898-908.

4. Ossio R, Roldán-Marín R, Martínez-Said H, Adams DJ, Robles-Espinoza CD. Melanoma: a global perspective. Nature Reviews Cancer 2017; 17: 393-4.

5. Noto G. On the clinical significance of cutaneous melanoma's precursors. Indian Dermatology Online Journal 2012; 3: 83-8.

6. Casula M, Colombino M, Satta MP, et al. Factors predicting the occurrence of germline mutations in candidate genes among patients with cutaneous malignant melanoma from South Italy. European Journal of Cancer 2007; 43: 137-43.

7. Godar DE, Subramanian M, Merrill SJ. Cutaneous malignant melanoma incidences analyzed worldwide by sex, age, and skin type over personal Ultraviolet-B dose shows no role for sunburn but implies one for Vitamin D3. Dermato-endocrinology 2017; 9: e1267077.

8. Niktabar SM, Latifi SM, Moghimi M, et al. Association of vitamin D receptor gene polymorphisms with risk of cutaneous melanoma. A meta-analysis based on 40 case-control studies. Dermatology Review/Przegląd Dermatologiczny 2019; 106: 268-79.

9. Leibeling D, Laspe P, Emmert S. Nucleotide excision repair and cancer. Journal of Molecular Histology 2006; 37: 225-38.

10. Paszkowska-Szczur K, Scott RJ, Serrano-Fernandez P, et al. Xeroderma pigmentosum genes and melanoma risk. International Journal of Cancer 2013; 133: 1094-100.

11. Li C, Hu Z, Liu Z, et al. Polymorphisms in the DNA repair genes XPC, $X P D$, and XPG and risk of cutaneous melanoma: a case-control analysis. Cancer epidemiology, biomarkers \& prevention : a publication of the American Association for Cancer Research, cosponsored by the American Society of Preventive Oncology 2006; 15: 2526-32.

12. Sobhan MR, Yazdi MF, Mazaheri M, Shehneh MZ, Neamatzadeh H. Association between the DNA repair gene XRCC3 rs861539 polymorphism and risk of osteosarcoma: A systematic review and meta-analysis. Asian Pacific Journal of Cancer Prevention 2017; 18.

13. Shimizu Y, Iwai S, Hanaoka F, and Sugasawa K. Xeroderma pigmentosum group $C$ protein interacts physically and functionally with thymine DNA glycosylase. The EMBO Journal 2003; 22: 164-73.

14. Nakamura T, Murakami K, Tada H, et al. Thymine DNA glycosylase modulates DNA damage response and gene expression by base excision repair-dependent and independent mechanisms. Genes to Cells 2017; 22: 392-405.

15. DiGiovanna JJ, Kraemer KH. Shining a Light on Xeroderma Pigmentosum. Journal of Investigative Dermatology 2012; 132: 785-96.

16. Hua R-X, Zhu J, Jiang D-H, et al. Association of XPC Gene Polymorphisms with Colorectal Cancer Risk in a Southern Chinese Population: A Case-Control Study and Meta-Analysis. Genes 2016; 7: 73.

17. He J, Shi T-Y, Zhu M-L, Wang M-Y, Li Q-X,Wei Q-Y. Associations of Lys939Gln and Ala499Val polymorphisms of the XPC gene with cancer susceptibility: A meta-analysis. International Journal of Cancer 2013; 133: 1765-75.

18. Wu H, Lv Z, Wang X, Zhang L, Mo N. Lack of association between XPC Lys939Gln polymorphism and prostate cancer risk: an updated meta-analysis based on 3039 cases and 3253 controls. International journal of clinical and experimental medicine 2015; 8: 17959-67.

19. Yu G, Wang J, Dong J, Liu J. XPC Ala499Val and XPG Asp1104His polymorphisms and digestive system cancer risk: a meta-analysis based on model-free approach. International Journal of Clinical and Experimental Medicine 2015; 8: 6621-30.

20. Zhang Y, Li Z, Zhong Q, et al. Polymorphisms of the XPC gene may contribute to the risk of head and neck cancer: a meta-analysis. Tumour Biology: the Journal of the International Society for Oncodevelopmental Biology and Medicine 2014; 35: 3917-31.

21. Blankenburg S, König IR, Moessner R, et al. Assessment of 3 xeroderma pigmentosum group $C$ gene polymorphisms and risk of cutaneous melanoma: a case-control study. Carcinogenesis 2005; 26: 1085-90.

22. Li C, Hu Z, Liu Z, et al. Polymorphisms in the DNA Repair Genes XPC, XPD, and XPG and Risk of Cutaneous Melanoma: a Case-Control 
Analysis. Cancer Epidemiology Biomarkers \& Prevention 2006; 15 : 2526-32.

23. Millikan RC, Hummer A, Begg C, et al. Polymorphisms in nucleotide excision repair genes and risk of multiple primary melanoma: the Genes Environment and Melanoma Study. Carcinogenesis 2006; 27: 610-8.

24. Figl A, Scherer D, Nagore E, et al. Single-nucleotide polymorphisms in DNA-repair genes and cutaneous melanoma. Mutation Research/ Genetic Toxicology and Environmental Mutagenesis 2010; 702: 8-16.

25. Gonçalves FT, Francisco G, de Souza SP, et al. European ancestry and polymorphisms in DNA repair genes modify the risk of melanoma: A case-control study in a high UV index region in Brazil. Journal of Dermatological Science 2011; 64: 59-66.

26. Ibarrola-Villava M, Peña-Chilet M, Fernandez LP, et al. Genetic polymorphisms in DNA repair and oxidative stress pathways associated with malignant melanoma susceptibility. European Journal of Cancer 2011; 47: 2618-25.

27. Oliveira C, Rinck-Junior JA, Lourenço GJ, Moraes AM, Lima CSP. Assessment of the XPC (A2920C), XPF (T30028C), TP53 (Arg72Pro) and GSTP1 (Ile105Val) polymorphisms in the risk of cutaneous melanoma. Journal of Cancer Research and Clinical Oncology 2013; 139: 1199-206.

28. Torres SM, Luo L, Lilyquist J, et al. DNA repair variants, indoor tanning, and risk of melanoma. Pigment Cell \& Melanoma Research 2013; 26: 677-84.

29. Zhou L, Lu Y, Yang G, Wu J. Quantitative assessment of the association between XPC Lys939Gln polymorphism and cutaneous melanoma risk. Tumor Biology 2014; 35: 1427-32.

30. Jiang W, Zhang H, Chen QW, Xie S. A meta-analysis of XPC Lys939Gln polymorphism and melanoma susceptibility. Journal of the European Academy of Dermatology and Venereology 2016; 30: 1327-31.

31. Yang X, Liu D, Wu H, et al. Association of XPC polymorphisms with susceptibility and clinical outcome to chemotherapy in breast cancer patients. Cancer Science 2012; 103: 1207-14.

32. Peng $\mathrm{Q}$, Chen Z, Lu Y, et al. Current evidences on XPC polymorphisms and gastric cancer susceptibility: a meta-analysis. Diagnostic Pathology 2014; 9: 96.
33. Wang Y, Li Z, Liu N, and Zhang G. Association between CCND1 and XPC polymorphisms and bladder cancer risk: a meta-analysis based on 15 case-control studies. Tumor Biology 2014; 35: 3155-65.

34. Sankhwar M, Sankhwar SN, Bansal SK, Gupta G, Rajender S. Polymorphisms in the XPC gene affect urinary bladder cancer risk: a case-control study, meta-analyses and trial sequential analyses. Scientific Reports 2016; 6: 27018.

35. Aghili K, Sobhan MR, Mehdinezhad-Yazdi M, et al. Association of GDF-5 rs143383 polymorphism with radiographic defined knee osteoarthritis: A systematic review and meta-analysis. Journal of Orthopaedics 2018; 15: 945-51.

36. Moghimi M, Kargar S, Jafari MA, et al. Angiotensin Converting Enzyme Insertion/Deletion Polymorphism is Associated with Breast Cancer Risk: A Meta-Analysis. Asian Pac J Cancer Prev 2018; 19: 3225-31.

37. Namazi A, Abedinzadeh M, Nourbaksh P, Neamatzadeh H. Association between the XRCC3 Thr241Met polymorphism and risk of colorectal cancer: A meta analysis of 5,193 cases and 6,645 controls. Asian Pac J Cancer Prev 2015; 16: 2263-8.

38. Namazi A, Forat-Yazdi M, Jafari M, et al. Association of interleukin-10 -1082 A/G (rs1800896) polymorphism with susceptibility to gastric cancer: meta-analysis of 6,101 cases and 8,557 controls. Arq Gastroenterol 2018; 55: 33-40.

39. Jafari-Nedooshan J, Moghimi M, Zare M, et al. Association of Promoter Region Polymorphisms of IL-10 Gene with Susceptibility to Lung Cancer: Systematic Review and Meta-Analysis. Asian Pac J Cancer Prev 2019; 20: 1951-7.

40. Moghimi M, Sobhan MR, Jarahzadeh MH, et al. Association of GSTM1, GSTT1, GSTM3, and GSTP1 Genes Polymorphisms with Susceptibility to Osteosarcoma: a Case-Control Study and Meta-Analysis. Asian Pac J Cancer Prev 2019; 20: 675-82.

41. Yazdi MF, Rafieian S, Gholi-Nataj M, Sheikhha MH, Nazari T, Neamatzadeh H. CYP2D6 Genotype and Risk of Recurrence in Tamoxifen Treated Breast Cancer Patients. Asian Asian Pac J Cancer Prev 2015; 16: 6783-7. 